NASA Technical Memorandum 85924

NASA-TM-85924

19850007447

The Western Aeronautical Test Range
of NASA Ames Research Center

Archie L. Moore

January 1985

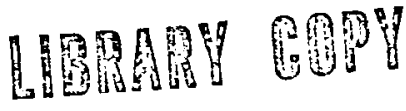

נ) 18935

LANGLEY RESEARCH CENTTER

LIERARY, NASA

HAMPTON, VIRGINIA 

NASA Technical Memorandum 85924

\section{The Western Aeronautical Test Range of NASA Ames Research Center}

Archie L. Moore

Ames Research Center, Dryden Flight Research Facility, Edwards, California

National Aeronautics and

Space Administration

Ames Research Center

Dryden Flight Research Facility

Edwards, California 93523 
.

. 
THE WESTERN AERONAUTICAL TEST RANGE OF NASA AMES RESEARCH CENTER

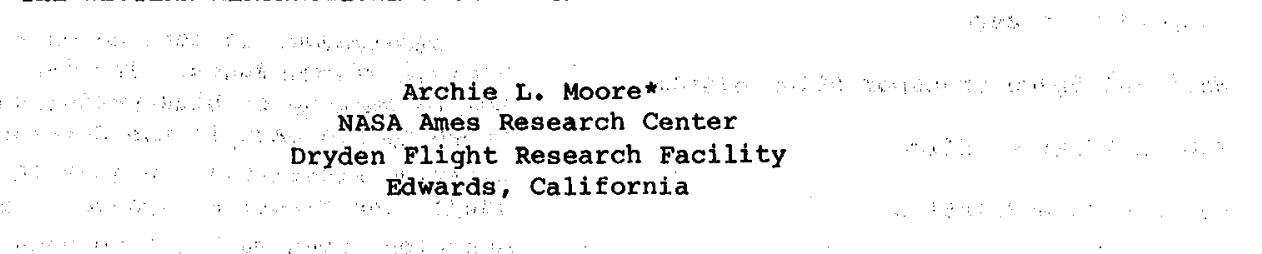

\section{Abstract}

An overview of the Western Aeronautiucal Test Range (WATR) of NASA Ames Research Center (ARC) is presented in this paper. The three WATR facilities are discussed, and three WATR elements - mission control centers, communications systems, real-time processing and display systems, and tracking systems - are reviewed. The relationships within the NASA WATR, with respect to the NASA aeronautics program, are also discussed.

\section{Introduction}

Researchers and support personnel are monitoring an experimental flight of a research aircraft in the mission control center (MCC, Fig. 1) at NASA Ames Research Center's Dryden Flight Research Facility at Edwards Air Force Base in southern California. One of the researchers, sitting at a work station displaying aircraft responses, notices an apparent anomaly and suggests to the flight controller that the pilot not proceed to the next flight test point until the anomaly is explained. As the engineer studies the data on a strip chart, he can hear the air-to-ground conversation between the pilot and controller - the controller takes advantage of this lull in test activity to say the aircraft is approaching the boundary of the restricted air space and the pilot should turn to stay within the restricted area.

In his search for more information, the researcher asks another researcher using the intercom system if she sees an anomaly on the real-time display that she has been monitoring. While she is calling up other pages of data to examine them, she suggests that another researcher, monitoring the flight by satellite link to the mission control center at the Ames Research Center at Moffett Field in northern California, may have some insight into. the problem. Looking at all the data, three researchers determine there is no anomaly and the experiment can continue. The flight plan is completed with no further interruptions and, as the aircraft lands, the three researchers and other researchers involved in this project discuss the further analysis of the data collected from this flight. As the mission control center empties, support personnel move quickly to reconfigure it to support the flight of a different research aircraft.

This scenario represents what is rapidly becoming a routine event in the operation of the NASA Western Aeronautical Test Range (WATR).: The NASA WATR supports test flying at three locations (Fig, 2): the Ames Research Center at Moffett Field Naval Air Station in northern California

\footnotetext{
*Manager, Western Aeronautical Test Range. Member, AIAA.
}

(Ames-Moffett), the Ames Research Center's Dryden Flight Research Facility at Edwards Air Force Base in southern California (Ames-Dryden), and the Crows Landing Facility at Crows Landing Naval Auxiliary Landing Field in California's Central valley (Crows Landing). Additionally, other remote sites can be linked by satellite. These three facilities have different types of support available, in accordance with their different roles, that have evolved since their initial development years ago.

This paper presents an overview of the NASA WATR at Ames Research Center (ARC). The facilities located at the three sites of the NASA WATR are discussed and general capabilities of four specific areas of the NASA WATR are reviewed. The relationships within the NASA WATR, with respect to handling of research data in flight test environment (Fig. 4), are also discussed.

\section{Nomenclature}

AFFTC Air Force Flight Test Centex

ARC Ames Research Center

$\mathrm{C} / \mathrm{C}$ command/control

COM

DFRF communications

DME Dryden Flight Research Facility

ETR distance measuring equipment

FM

GSFC

$\mathrm{HF}$

IFTIS Eastern Test Range

frequency modulation

Goddard Space Flight Center

high frequency

integrated flight test information system

IRIG

interrange instrumentation group

JSC

Johnson Space Center

KSC

Kennedy Space Center

MCC

mission control center

MDD

mate/demate device

MET meteorological

MLS

NACA

microwave landing system

NASA
National Advisory Council on Aeronautics

National Aeronautics and Space Adminis tration 


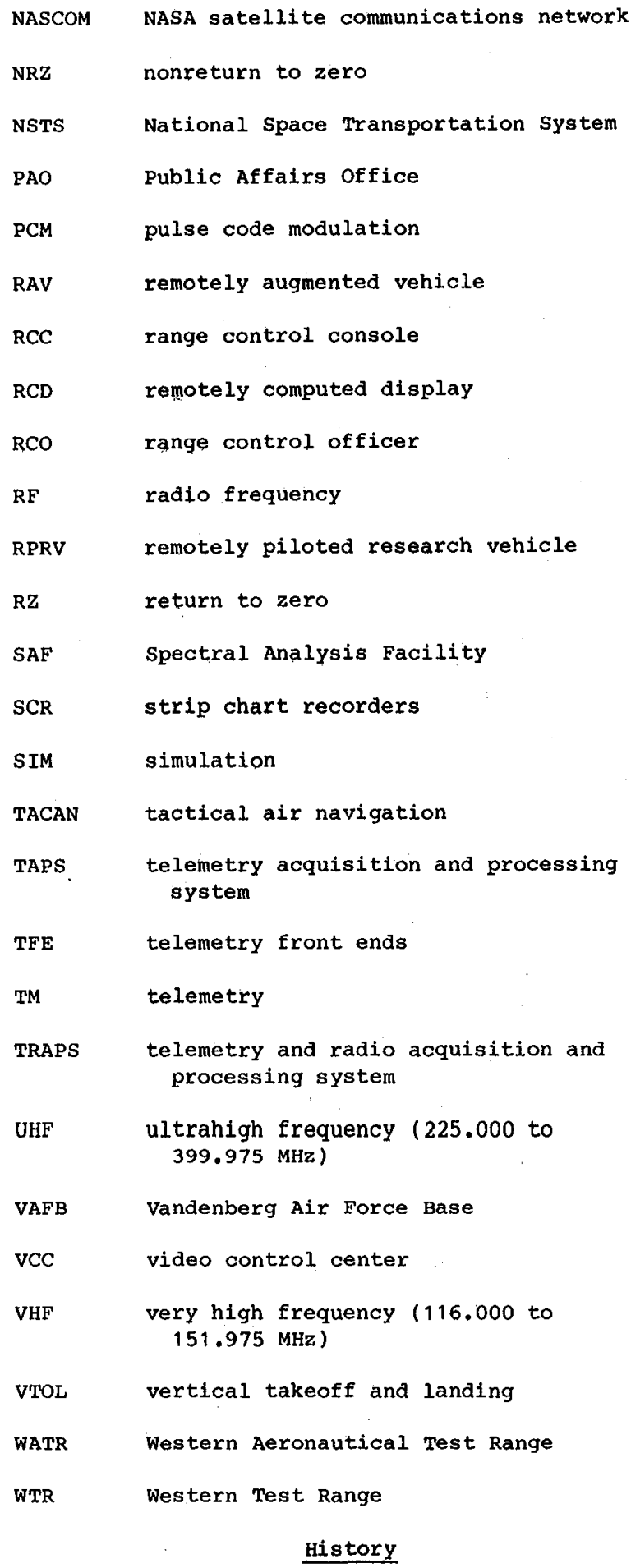

In the time scale of history, the time since the first level supersonic flight on October 14, 1947 above the Muroc Range is a fraction of a second. Aircraft performance has increased, aircraft system complexity has taken quantum jumps, the amount of data telemetered to the ground has grown beyond human comprehension, and the necessity for computer-augmented control of flight has become a reality. This increase and dramatic growth of aeronautics program requirements (Fig. 3) has placed, and continues to place, increasing demands on ground-based experimental facilities required to support research flight tests in its role of "pushing the edge of the envelope."

Ames-Dryden is located on a section of the historic Muroc Range. The facility is oriented toward testing of high-performance aircraft, as shown by its part in the development of the $x$-series aircraft. 1 In just 20 years (1947 to 1967), the $X$-series expanded the manned flight enevelope from Mach 1.0 to Mach 6.7 (Table 1).2 The present Ames-Dryden facility is the result of an evolutionary process that began in 1946 when the National Advisory Committee on Aeronautics (NACA) established the High-Speed Flight Test Station as part of the effort toward sustained supersonic flight. As the $x$-plane programs grew, so did the data-gathering and ground facility capabilities. In 1959, the facility, redesignated the Flight Research Center (FRC), established an aerodynamic test range and terminal recovery area for the $x-15$ aircraft. Testing this hypersonic aircraft required a large geographic area and sophisticated data acquisition capabilities. Testing of highperformance and exotic aircraft, including lifting bodies (predecessors to the space shuttle) and advanced remotely piloted aircraft, has continued. The most recent arrival is the $\mathrm{X}-29 \mathrm{~A}$ forward-swept wing aircraft. The Centex, renamed the Hugh $L$. Dryden Flight Research Center in 1976, merged with the Ames Research Center in 1981 and was designated the Dryden Flight Research Facility.

Ames-Moffett is oriented toward the testing of rotary aircraft and the support of a variety of space science aircraft used in astronomical, atmospheric, and earth-resources research. The Ames Research Center at Moffett Field was established in 1940 by NACA as a center for wind tunnel and other aeronautical research. In addition, a variety of experimental aircraft are tested at ARC. As the areas of research at the center widened, so did the types of aircraft flown, including airborne astronomical observatories, atmospheric sampling aircraft, and high-altitude photo-reconnaissance aircraft. In 1977, NASA consolidated its helicopter research and located it at Ames-Moffett. Much of the current aircraft research is directed toward operational concerns, including noise reduction, fuel efficiency, and improved operation in terminal control areas.

Increasing congestion and urbanization in the area around Ames-Moffett led, in 1973, to the development of Cxows Landing as a test facility. The Crows Landing facility supports only flight testing itself; no aircraft or researchers are permanently housed at this site. Rather, the aircraft and the researchers are ferried to the site for experiments. When the facility was developed, a data link to Ames-Moffett was developed.

The 1981 consolidation of the Dryden Flight Research Center and the Ames Research Center led directly to the consolidation of the aeronautical test range facilities at the three sites into the unified NASA Western Aeronautical Test Range.

The NASA Western Aeronautical Test Range (WATR)

The NASA WATR supplies tracking, data acquisition, and real-time processing at Ames-Dryden (Fig. 5), Ames-Moffett (Fig. 6), and Crows Landing 
(Fig. 7). The elements of the WATR are the mission control centers, communications systems, real-time processing and display systems, and tracking systems (Fig. 8).

A user of the NASA WATR considers the mission control center the most visible element of the WATR; the MCC supports the three systems. The monitoring of aircraft in flight is the manifestation of a complex system of real-time data acquisition, processing, and display. The integration of the system areas (Fig. 9) in the MCCs presents the user, client, or researcher with one of the most comprehensive flight research and test facilities in the free world.

\section{Mission Control Centers}

The mission control centers (MCCs) are where the results of the NASA WATR come together. It is here that the user judges the worth of the WATR. Because mission profiles have differed in the past, the physical configurations and capabilities of the MCCs located at Ames-Dryden and AmesMoffett differ considerably. These differences should begin to disappear as functions of the facilities become more similar.

The two MCCs at Ames-Dryden, a Blue Room (Fig. 10) and a Gold Room, are mirror images of each other. The researcher/analyst real-time monitoring workstations are located around the perimeter of the room, and three "control" consoles are in the center of the room. The space position displays and an array of video monitors with selectable programing are in the front of the room. When facing the front of the room the console to the left is the range control console (RCC, Fig. 11). This console, the focal point for range operations, is staffed by the range control officer ( $\mathrm{RCO}$ ). The RCO's function is to determine how well the WATR is operating. The RCO uses selected circuits of the 150-channel range communication system (RACOMM) to be in constant communication with as many WATR facilities as are in operation for the particular mission, depending on the mission underway.

During a remotely piloted research vehicle/ remotely augmented vehicle (RPRV/RAV) or remotely computed display (RCD) mission, the RCC is linked with the remotely commanded vehicle facility. The console is linked with the remote sites of the WATR, such as the communications building and the two aeronautical txacking sites, and during a National space Transportation System (NSTS, or space shuttle) operation, it is part of a worldwide communications network. The remote channelization of UHF and VHF radios located in the communications building can be controlled through the RCC.

The console located to the right of the RCC.is the project/program control console (Fig. 12). It provides necessary information for the user to decide if the data being collected during the mission are appropriate, and it enables the user to assess the quality of data. Aata engineer or an individual responsible for the onboard data system is usually seated at this console, as is the principal investigator, project engineer, or project manager. The console has an intexactive display that allows call-up of different preprogrammed cathode ray tube (CRT) data displays to aid in the tasks. Personnel have access to several of the RACOMM circuits to assist in communications with researchers who are monitoring the research content of the data at the workstations around the room.

Selectable programmable video displays are also at the project/program control console. These dis plays are provided by the video switching matrix located in the video control center. The third individual at this console, the flight controller, is responsible for the coordination of the research aircraft, its safety chase, and the Edwards AFB control tower. The controller at Ames-Dryden is concerned with the location of the test vehicle with respect to the many controlled areas of the Air Force Flight Test Center (AFFTC) flight complex. This flight controller relies heavily on the space position displays at the front of the room which display the aircraft with respect to the many controlled test areas. These displays, which have been pen-and-ink plot boards in the past, are large-screen CRT devices.

The final console in the front of the room is the flight safety and flight operation console (Fig. 13). It has the provision for an air traffic controller, in the event that a mission is planned to go beyond the controlled airspace of the AFFTC. The aircraft operations engineer, usually located at this console, is responsible for the vehicles and is available during emergencies. There is a provision for a safety officer to be at this console if the mission requires that level of monitoring and support. The safety and flight operations console has selected RACOMM circuits and video displays with selectable programming from the video control center. There is also a selectable preprogrammed CRT data display for flight critical safety parameters provided on a 19-inch color monitor.

The key research consoles are those located around the perimeter of the room. These six consoles display real-time data to the researchers in the MCC. They are, in general, configured alike with only slight differences (Fig. 14). Each console is constructed with a three-bay, 19-inch rack superstructure. There are two strip chart recorders (SCR) located in each console, and each console is equipped with a 19-inch color monitor for the display of alphanumeric data displays, computer graphics representations of enunciator panels, or graphics displays including cross plots and alphanumeric information. A portion of the console can be used in an interactive mode in real-time with the real-time processing and display system. All consoles have access to preprogrammed CRT data displays, and each console has access to ten of the RACOMM circuits. These circuits monitor air-toground mission audio as well as "hot-mike" downinked from the vehicle. Some of these circuits can be configured into localized intercom circuits for researchers to communicate during the mission.

A final provision in the MCCs is that of a Public Affairs office (PAO) console (Fig. 15). This console has access to all video inputs supplied from the video control center on three 5-inch monitors. Two of these monitors act as preview monitors, and a third monitor displays information that is being transmitted by way of a satellite 
called NASA-SELECT. This information is transmitted to any site having a NASA satellite communications network (NASCOM) terminal or access to a NASCOM terminal. A remotely controlled camera with a zoom lens is located above this console. This allows the PAO console operator to zoom in on any of a number of the displays in the MCC or zoom back to see the operation of the MCC for release on NASA-SELECT.

\section{Communications Systems}

The communications systems area of the NASA WATR is subdivided into three specific system areas to support real-time research flight test at the ARC: a radio frequency ( $R F$ ) audio system, a ground audio system, and a video system.

Radio Frequency Audio system. The RF audio system provides the user with the full spectrum of air-to-ground frequencies in the HF, VHF, and UHF frequency ranges. Frequencies are selected in the MCCs from a remote channelization system. At AmesDryden, this system tunes the transceiver in the WATR communications building, does a closed-loop transmit and receive test, and signals the MCC with a "ready" indication. Each MCC has access to five dedicated UHF transceivers, three VHF transceivers, and one $\mathrm{HF}$ transceiver. The VHF transceivers operate at $20 \mathrm{w}$ power with optional frequency amplifiers that will boost output power to $100 \mathrm{~W}$, when required. The VHF transceivers operate at $25 \mathrm{~W}$ output power. In addition to these transceivers, the WATR maintains a set of five UHF receivers and three VHF transmitters dedicated to support of NSTS space shuttle missions. These systems are maintained in the WATR communications building (Fig. 16). The building also houses a mission audio recording capability on a 7-channel reel-toreel recorder or on a standard cassette recorder.

The RF audio system at crows landing is a sixchannel system that is pretuned to the frequencies designated for a given mission. Three VHF, one UHF channel, and an intercom system provide audio support.

The Ames-Moffett RF audio system has the capability to simulcast one UHF and three VHF channels.

Ground Audio System. The ground audio system at Ames-Dryden is centered around the RACOMM system and consists of a 150-circuit ground communications network that ties all the necessary facilities of the NASA WATR together to support agency aeronautics and space program missions. The network is connected to the NSTS network for shuttle missions by way of NASCOM.

video system. The video system, used to support all missions conducted in any of the NASA WATR MCCs, is capable of supplying the user with any of 20 video sources. At selected locations in the MCCs (Fig. 17) and throughout the WATR, the user can select these video sources by way of a channel selector. At other locations throughout the complex, the user receives the selection provided from the NASA WATR video control centex (VCC). The VCC is the routing center for all video sources and destination within the Ames-Dryden facility. The vCC also provides, to selected locations, an audio program to complement the video program. This audio can be a mix of any or all of 15 audio sources ranging from air-to-ground mission audio to audio provided by way of the NASA-SELECT satellite.

\section{Real-Time Processing and Display Systems}

The real-time processing and display systems area is centered around an architectural concept of a cluster of super minicomputers supplying highspeed data processing to fill a current values table. This table then supplies engineering units data to the WATR mission control centers by way of a high-speed data bus (Fig. 18). Real-time user/ client workstations in the MCCs "listen" to that data bus and supply real-time information and displays for mission decisions.

This area includes the following functions: telemetry acquisition processing, telemetry processing, radar processing, high-frequency data processing, real-time display generation, and postmission processing.

Telemetry acquisition processing includes both FM/FM and PCM/FM data streams. The FM/FM systems installed at Ames-Dryden consist of two 18-channel proportional bandwidth stations and twelve 6channel constant bandwidth stations. The proportional bandwidth subsystem uses three reference oscillators with frequencies of $22 \mathrm{kHz}, 25 \mathrm{k} \mathrm{Hz}$, and $100 \mathrm{kHz}$. The stations also use the standard interrange instrumentation group (IRIG) narrow-band standard. The constant bandwidth systems use $128 \mathrm{kHz}$ reference discriminators and tape speed compensation electronics.

The PCM formats supported by the WATR include: nonreturn to zero (NRZ), return to zero (RZ), and biphase and delayed modulation (Miller code). Downlink PCM streams are routed to telemetry front ends (TFE) with the necessary bit synchronizers, main frame synchronizers, and subframe synchronizers to handle 200,000 words pex sec. The TEEs are equipped with simulators for aid in premission setup. The PCM streams are merged, compressed, and converted to engineering units by a telemetry acquisition processor. The engineering units are then placed in a shared memory where they are accessible for use in real-time computations that are displayed in the MCCs. These computations range from the very simple such as summing two surface positions to get total surface effect to very sophisticated functions such as complete engine decks that emulate (with computer code) the operation of state-of-the-art fanjet engines. The computation set for most vehicles includes computations for air data (such as Mach number, dynamic pressure, and geopotential altitude), gross weight and center of gravity, and safety of flight parameters. Processed radar information is also placed in the current values table for processing and display in real-time. Currently, high-frequency data analysis is performed on a separate processor. In the near future, this process will be integrated into the new architectural concept called telemetry and radar acquisition and processing system (TRAPS). The current and subsequent versions of the TRAPS concept have the capability to capture data to be used in post-mission processing and in real-time. This capability greatly enhances the turn-around time for a given project and, in general, any mix of several projects. 
Detailed descriptions of actual displays were discussed in the Mission Control Centers section. The displays now appearing in the MCCs are generated in the super minicomputers in the TRAPS cluster. It is planned that in the future this display generation can be accomplished in the realtime user/client workstations in the MCCs.

\section{Tracking systems}

The tracking systems of the NASA WATR provide the basic antenna systems for range operations. Included in this systems area are the timing systems necessary to time-correlate data acquired during real-time missions. The antenna systems located at the different sites of the NASA WATR have differed in type primarily because of differences in missions of the three sites.

At Ames-Dryden, the primary vehicle acquisition system is an FPS-16 C-band precision tracking "radar (Fig. 19). The FPS-16 radar is a high-accuracy, long-range amplitude-comparison, monopulse radar capable of manual or automatic target acquisition of either aerodynamic or orbital targets." A selection is provided for the use of single-pulse outputs for skin tracking or code-pulse-group outputs for beacon tracking. The transmitter provides 1 MW of peak power output over a range of 5450 to $5815 \mathrm{MHz}$ (C-band). During remotely piloted research vehicle (RPRV) testing, the prime frequency is assigned to the drop vehicle and another frequency, to the launch vehicle. Output power compensation is provided in the microwave section to reduce transmitter output power as the target range decreases to increase the dynamic range of the receiver during skin tracking and to prevent saturation during beacon tracking. The FPS-16 system is capable of tracking targets from $457 \mathrm{~m}$ to $32,767 \mathrm{n}$. mi. During the operation of the FPS-16 system, reflected signals or beacon returns are received by the antenna comparator which derives three outputs: a reference signal, an azimuth error signal, and an elevation error signal. A receiver range gate, generated by the range timing section, eliminates interference resulting from transmitter pulse leakage, ground clutter, and other external signals by enabling the error and reference detectors in the receiver only during the time the target is received. A duplexer is used to prevent high-level transmitter energy from entering the receiver during transmitter "on" time and permits the reference signal to entex the receiver during the transmitter "off" time. The FPS-16 is equipped with boresight optics for manual tracking and system calibration.

One of the principal telemetry tracking systems at Ames-Dryden is a 20-ft-diameter parabolic triplexed antenna system (Fig, 20). The triplex system is on a 2680-ft microwave landing system (MLS) ridge overlooking the takeoff and landing area. It provides the simultaneous reception of downlinks in the $\mathrm{S}-, \mathrm{L}$ - and $\mathrm{C}$-band frequency ranges. It can, at the same time, transmit command uplink in the L-band range. Four sets of two receivers and a combiner allow for the reception of the PCM/FM downlinks. Two receivers allow for C-band video downlink. Downlink telemetry and video is received on frequencies between $4530 \mathrm{MHz}$ and $4830 \mathrm{MHz}$. Command uplink is transmitted on 1804.5 $\mathrm{MHz}$. The normal operating radius for the system is $200 \mathrm{n}$. mi.
The pairing of receivers allows for the reception of two separate frequencies of telemetry downlink data with each channel's polarization being remotely controlled. The pairs of receivers are used in conjunction with diversity combiners that allow reception of four diversity combined telemetry frequencies or up to eight separate telemetry frequencies with circular polarization. Downlink video uses the same concept of receiver pairs in conjunction with combiners... The command uplink signals are transmitted at $100 \mathrm{~W}$ continuous wave with the modulation provided by the remotely commanded vehicle facility or the previously mentioned real-time processing and display system. The triplex antenna system is positioned by autotracking the telemetry downlink carrier, allowing stand-alone operation, and slaving to the EPS-16 radar or a MK-51 optical tracker. When the system is operated in the manual mode, boresight optics aid in target acquisition.

A second telemetry tracking system was installed on the main Ames-Dryden building (Fig. 21). It is a 12-foot parabolic antenna carried on an elevation-over-azimuth pedestal, and it is used to receive and autotrack in the frequency band from $1435 \mathrm{MHz}$ to $2400 \mathrm{MHz}$. Frequency use within these limits is $1435 \mathrm{MHz}$ to $1540 \mathrm{MHz}$ for L-band telemetry, $2200 \mathrm{MHz}$ to $2400 \mathrm{MHz}$ for S-band telemetry, and $1727 \mathrm{MHz}$ for downlink video. The system uses a conically scanning RF feed assembly to autotrack on all received frequencies. Vertically and horizontally polarized receiving elements feed dual receiver channels that culminate in an optimal combiner similar to the triplex antenna system. Four sets of vertical and horizontal receivers and their combiners are presently available for vehicles while simultaneously receiving video downlink on a fifth receiver/combiner set. The capacity exists for future expansion to eight channels. The boresight optics included in the system can be used to aid in manual tracking.

The final tracking antenna system at AmesDryden is on the WATR communications building. It is a high-gain log periodic with a 12-foot dish. The antenna is used for long-range UHF communications and as a backup for the uplink of command information. This antenna system is equipped with boresight optics.

At Crows Landing, highly accurate space position information is supplied for terminal area and vertical takeoff and landing (VTOL) work. Two Nike Hercules, X-band monopulse radars are used to skin or beacon track aircraft (Fig. 22). The range of the track is 250 yd to 200,000 yd. Because this facility is primarily used for terminal area research programs, the problem of multipath has been circumvented by the use of a laser tracker mounted on one of the radar systems. The laser provides tracking accuracy at close range, 250 yd to $20,000 \mathrm{yd}$. video boresight cameras augment the tracking system and provide visual contact with the aircraft to enhance performance. The improved Nike Hercules radar operrates at X-band frequencies, $8500 \mathrm{MHz}$ to $9600 \mathrm{MHz}$, with a pulse repetition frequency of 500 pulses per sec and a peak power output of $250 \mathrm{kw}$. In the beacon mode, the radar transmits at $9000 \mathrm{MHz}$ and receives at $9400 \mathrm{MHz}$. The configuration also includes digital range and optical angle digital readout. 
The laser tracker is mounted on the target track radar. The optical transmit/recelve axis of the laser is offset from the radar RF axis by approximately $5 \mathrm{ft}$ and is on the elevation axis. The NiYag laser is invisible to the human eye. Its peak power output of 1 MN is hazardous to the human eye and appropriate safety procedures have been implemented to ensure safe operation in the airport area. The tracker is a monopulse system similar to the radar and provides servo tracking signals and a range word. The laser operates at a pulse rate of 100 pulses per sec. In a typlcal operation, the test vehicle is acquired by the radar, and a transition to the laser tracker occurs when a positive signal is received.

The other unique space position device located at Crows Landing is a microwave landing system (MLS). The MLS is a C-Band ground-based airderived system providing distance and angular position information relative to antennas located in the vicinity of the Crows Landing runway. It consists of three basic elements: the azimuth angle system, the elevation angle system, and the precision distance measuring equipment (DME). The azimuth angle system provides azimuth angle information through an $82^{\circ}$ arc, centered on the runway centerline. The elevation angle system provides elevation angle information over the $1.2^{\circ}$ to $13.6^{\circ}$ range throughout a $90^{\circ}$ arc centered on the runway centerline. The precision DME provides range information throughout the azimuth coverage area. Azimuth, elevation, and five MLS data words are transmitted on the same frequency of $6.0601 \mathrm{GHz}$ (channel 97). The precision DME is compatible with conventional L-band DMEs, but has a precision capability to permit overall accuracies of well under $100 \mathrm{ft}$ within $7 \mathrm{n}$. mi. of the ground station. The DME operates on channel $49 x$ (1073 MHz a/g, $1010 \mathrm{MHz}$ $g / a)$.
The space position information acquired from the systems is transferred to the real-time processing and display system at 20 samples per sec. These data are then available for local display in the MCC located at Crows Landing or shlpped by way of land lines and a telemetry repeater system to Ames-Moffett for display in the MCC located there.

\section{Concluding Remarks}

The NASA Western Aeronautical Test Range offers a unique integration of all the equipment and systems necessary to perform research flight test. These capabilities are realized in the mission control centers of the WATR. The systems continue to evolve to meet the future needs of the Agency's aeronautics and space programs. The primary goal of the WATR and its staff is to provide the user with more computed answers and less raw data in real time. Given the type of aircraft and the integration of systems onboard, this goal is imperative and can be realized through evolution. The WATR will continue to supply the user/client with information in real-time while building new systems to supply even more of the same in the future. This goal and its associated approach will continue to maintain the NASA WATR as the premier facility of its type in the inventory.

\section{References}

${ }^{1}$ szalai, Kenneth J., "Role of Research Aircraft in Technology Development," NASA TM-85913, 1984.

${ }^{2}$ Spearman, M. L., "Historical Development of World Wide supersonic Aircraft," AIAA Paper 79-1815, AIAA Aircraft Systems and Technology Mtg., New York, N.Y., Aug. 20-22, 1979.

Table 1. Expansion of the manned flight envelope

\begin{tabular}{|c|c|c|c|}
\hline Aircraft & Event & Date & Pilot \\
\hline$x-1$ & Mach 1.06 & October 14,1947 & Yeager \\
\hline$x-1$ & Mach 1.45 & March 26, 1948 & Yeager \\
\hline D558-II & Mach 1.87 & August 7,1951 & Bridgeman \\
\hline D558-II & Mach 2.005 & November 20,1953 & Crossfield \\
\hline$x-1 A$ & $\begin{array}{r}\text { Mach } 2.435 \\
74,200 \mathrm{ft}\end{array}$ & December 12, 1953 & Yeager \\
\hline $\begin{array}{l}x-1 A \\
x-2\end{array}$ & $\begin{array}{l}90,443 \text { ft } \\
\text { Mach } 2.87\end{array}$ & $\begin{array}{l}\text { August } 26,1954 \\
\text { July 23, 1956 }\end{array}$ & $\begin{array}{l}\text { Murray } \\
\text { Everest }\end{array}$ \\
\hline$x-2$ & $126,200 \mathrm{ft}$ & September 7, 1956 & Kincheloe \\
\hline$x-2$ & Mach 3.2 & september 27,1956 & Apt \\
\hline$x-15$ & $354,200 \mathrm{ft}$ & August 22,1963 & Walker \\
\hline$x-15$ & Mach 6.7 & October 3, 1967 & Knight \\
\hline
\end{tabular}




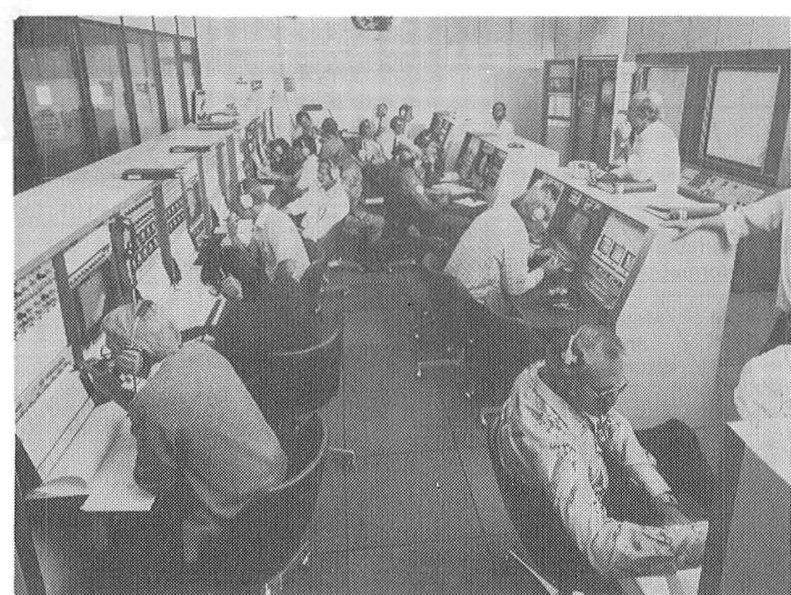

ECN 20640

Fig. 1 WATR Blue Room mission control center.

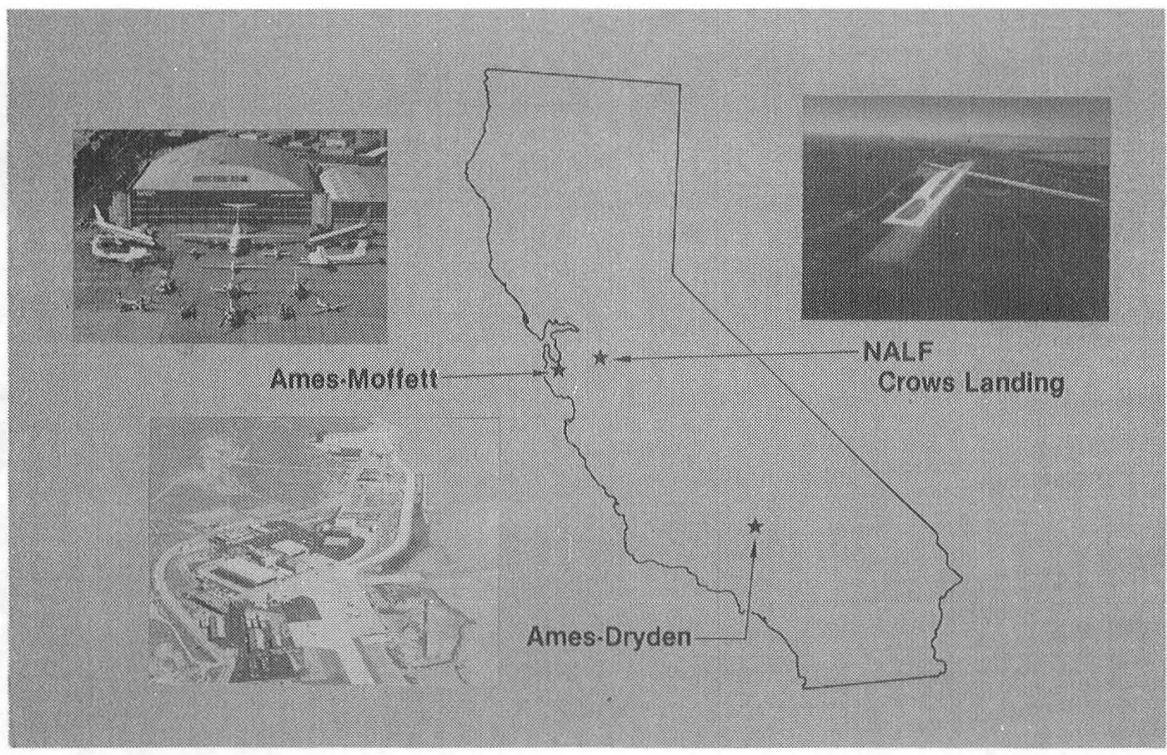

AD84-765a

Fig. 2 Western Aeronautical Test Range. 


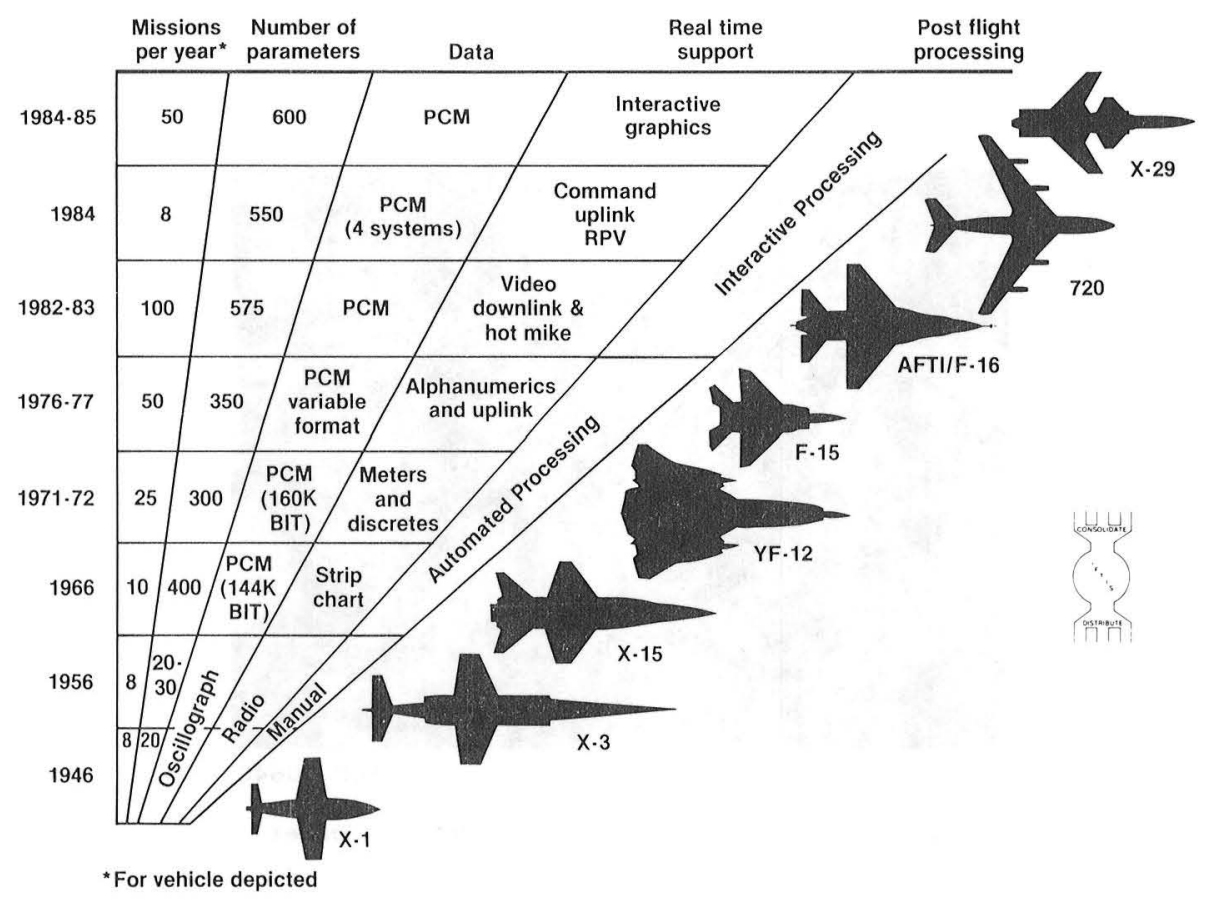

Fig. 3 Evolution of aeronautics program requirements.

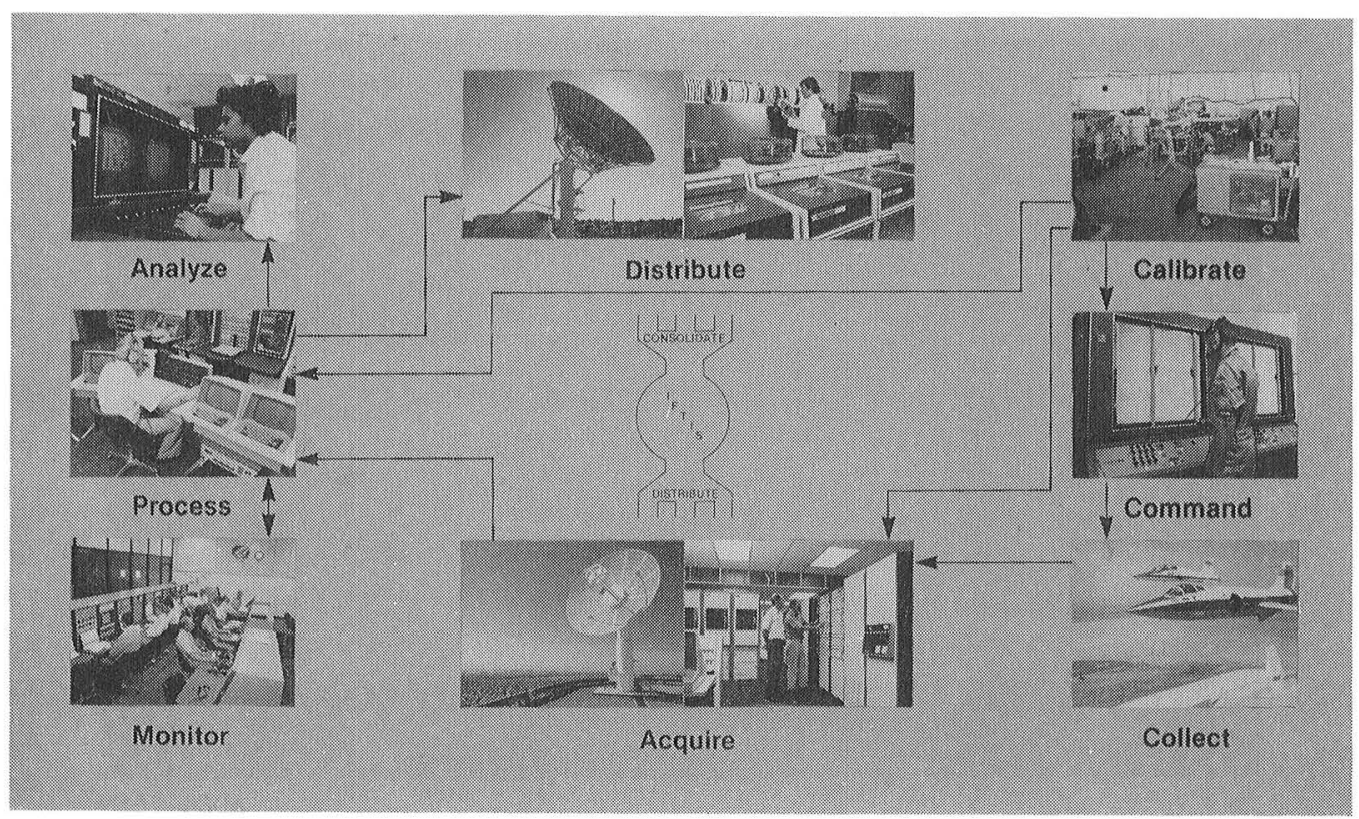

DFRC $80-522$

Fig. 4 Handling research data in the flight test environment. 


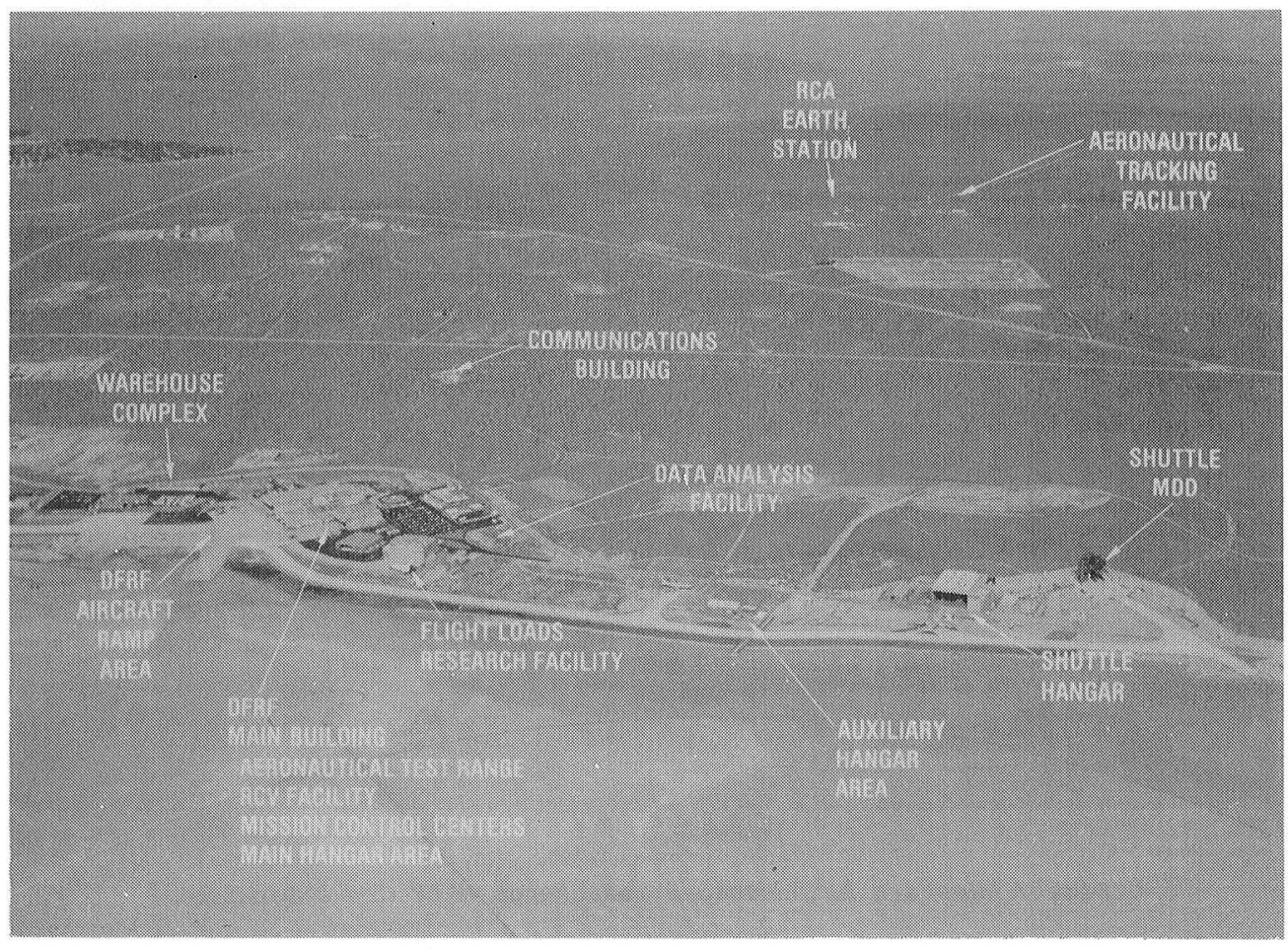

ADFRF83-268b

Fig. 5 Hugh L. Dryden Flight Research Facility.

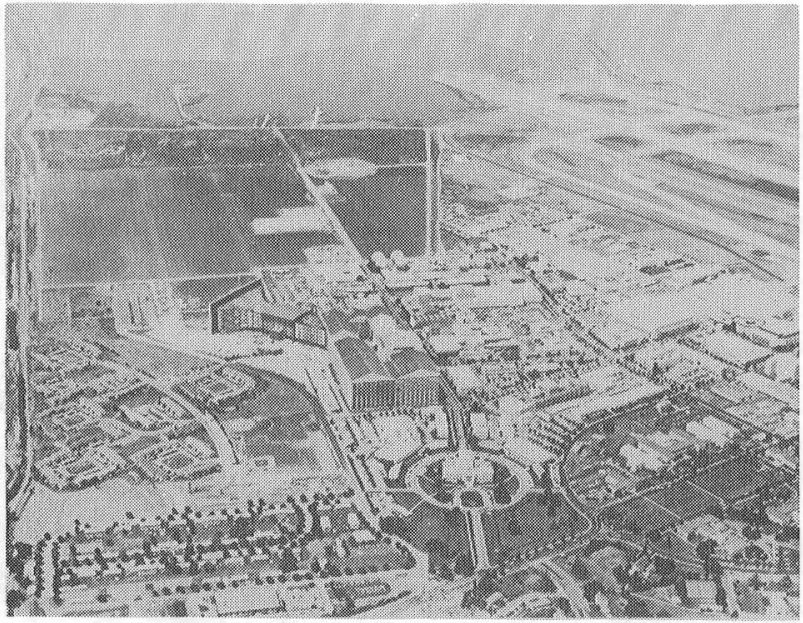

ECN 25681

Fig. 6 Ames Research Center. 


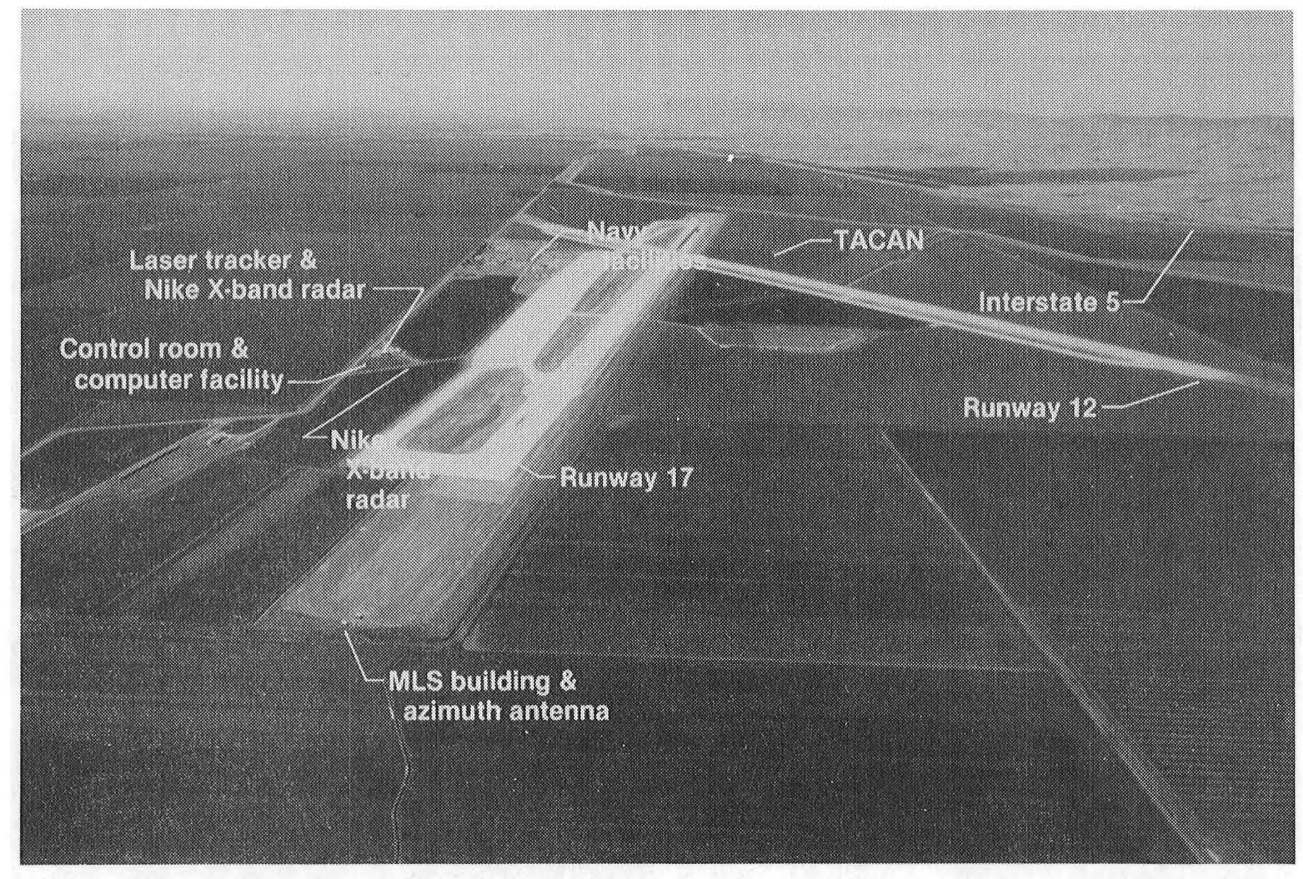

AD83-819a

Fig. 7 Western Aeronautical Test Range NALF Crows Landing.

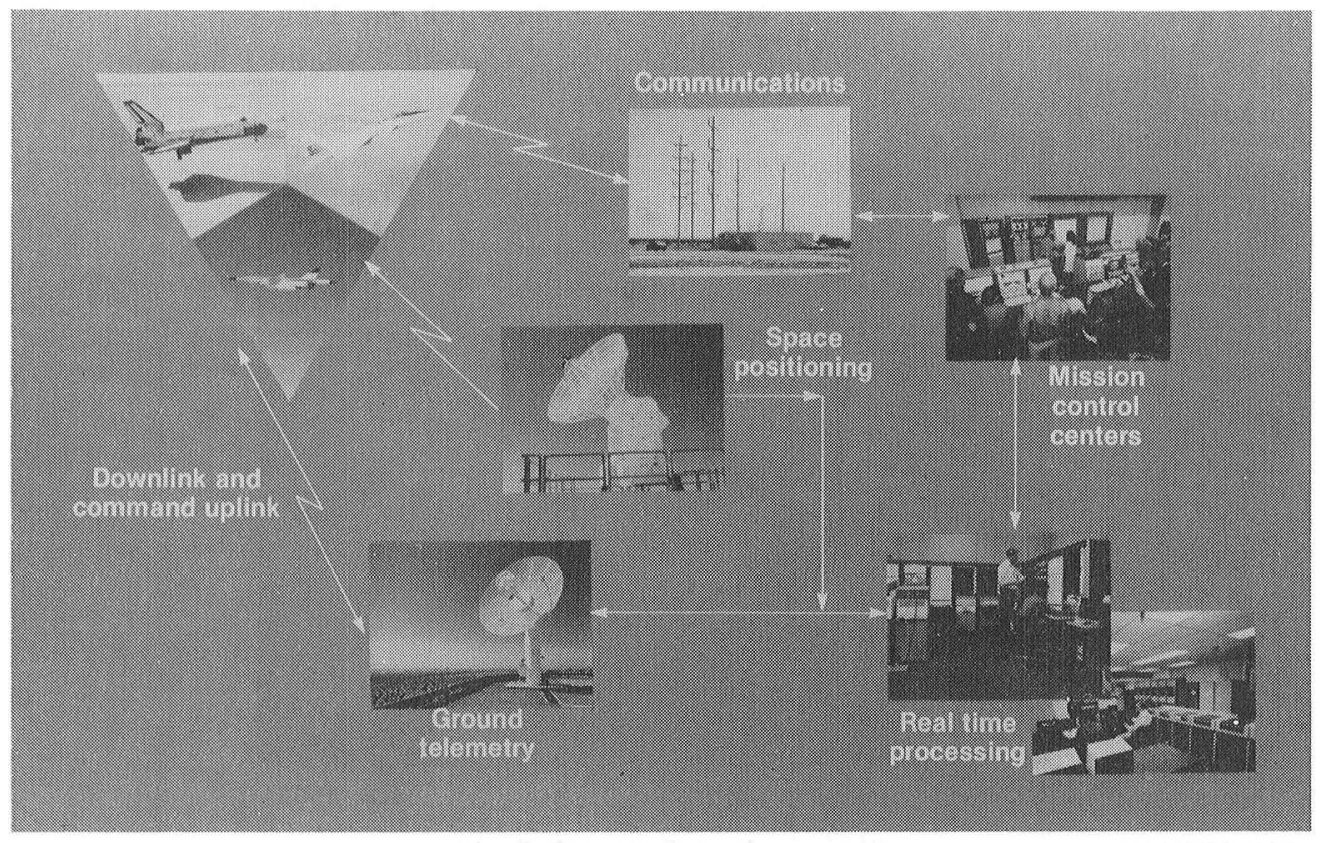

ADFRF82-916C

Fig. 8 Major functional areas of the test range. 


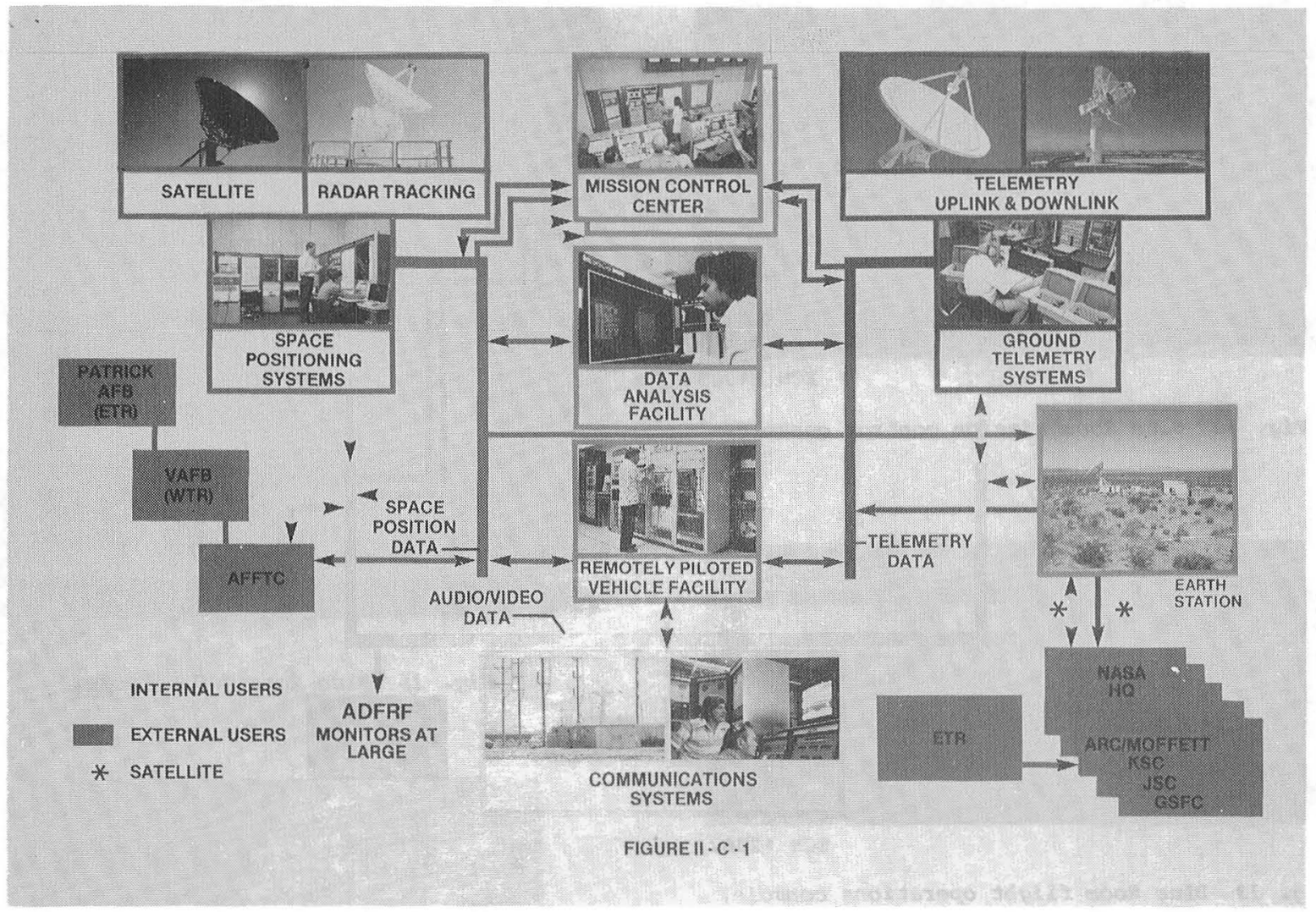

AD80-294d

Fig. 9 WATR systems and their interfaces.

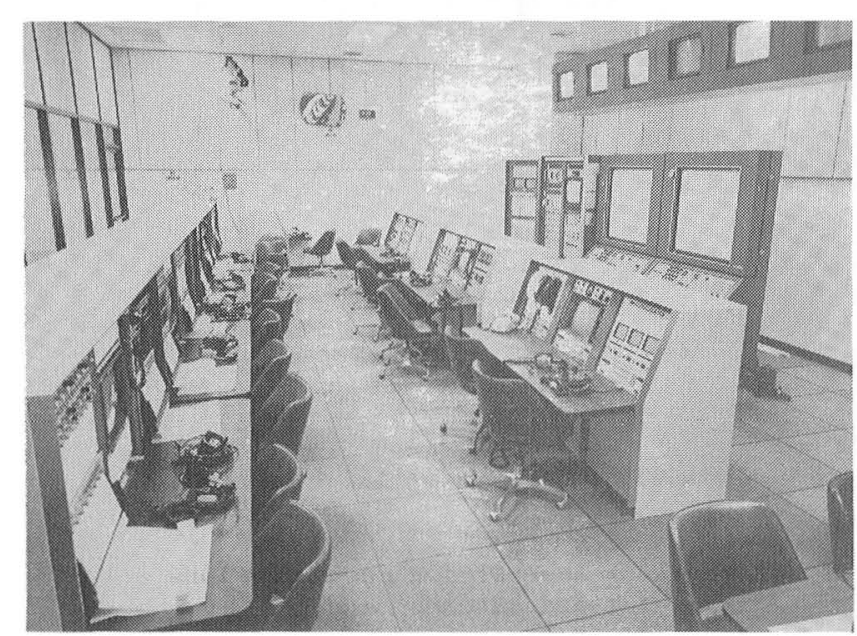

ECN 20643

Fig. 10 Mission control center Blue Room.

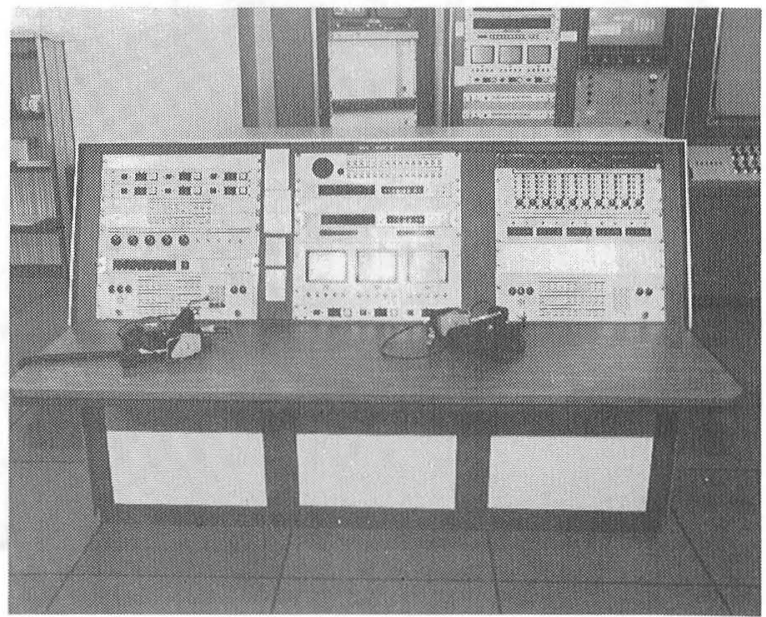

ECN 31791

Fig. 11 Blue Room WATR control console. 


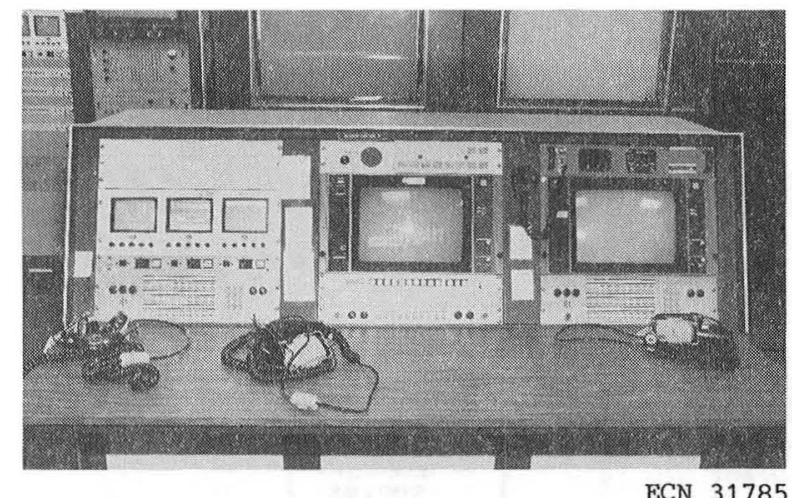

Fig. 12 Blue Room mission control console.

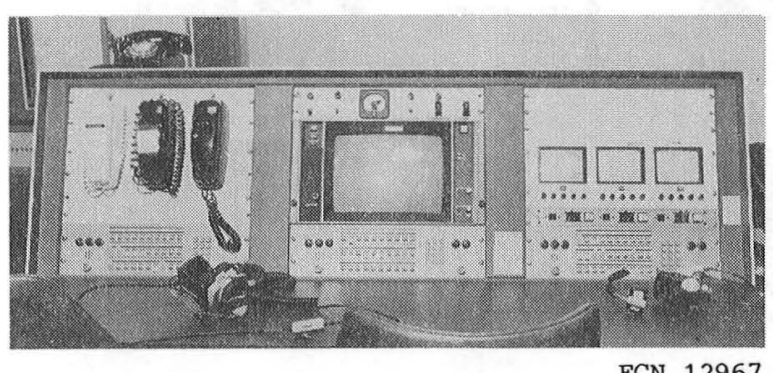

Fig. 13 Blue Room flight operations console.

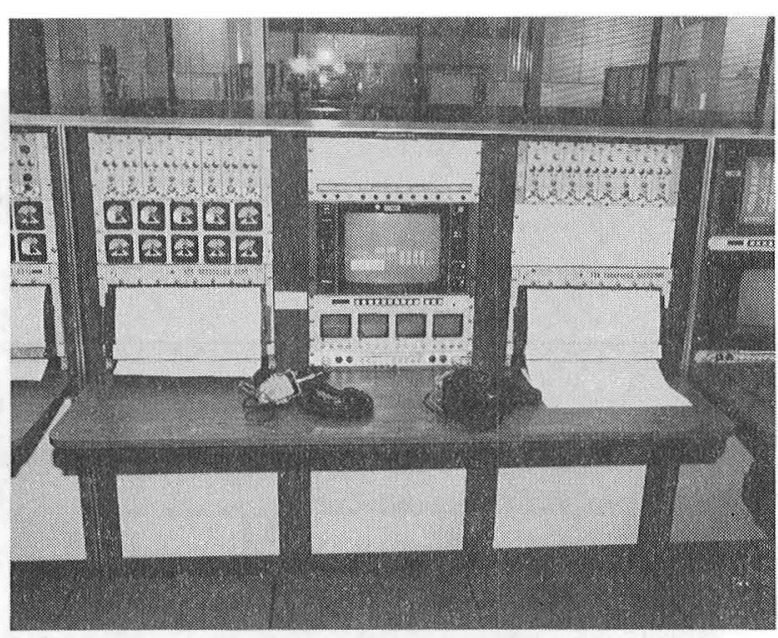

ECN 31789

Fig. 14 Blue Room analyst console \#4.

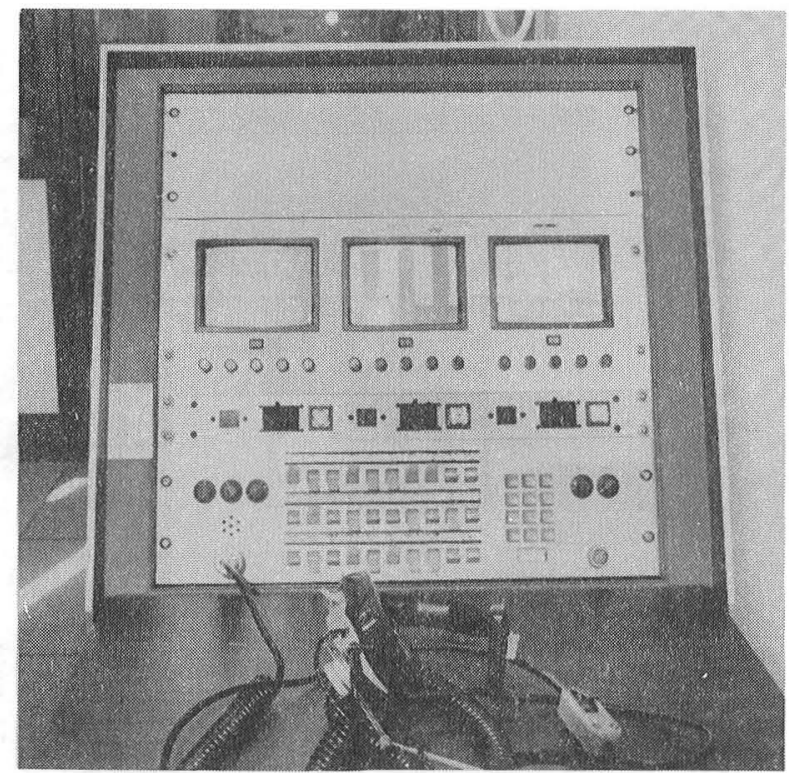

ECN 12971

Fig. 15 Blue Room PAO console.

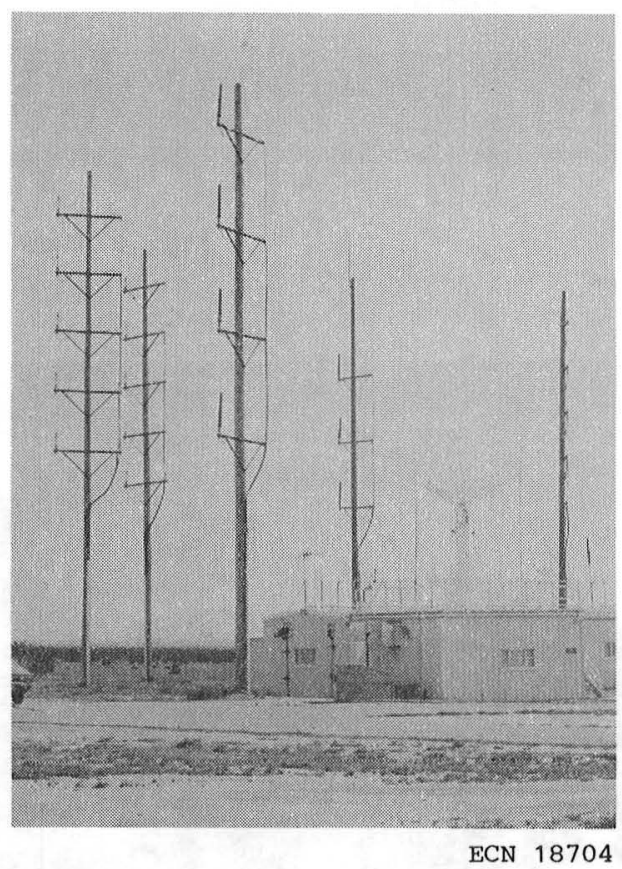

Fig. 16 Ames-Dryden communications building and antenna farm. 


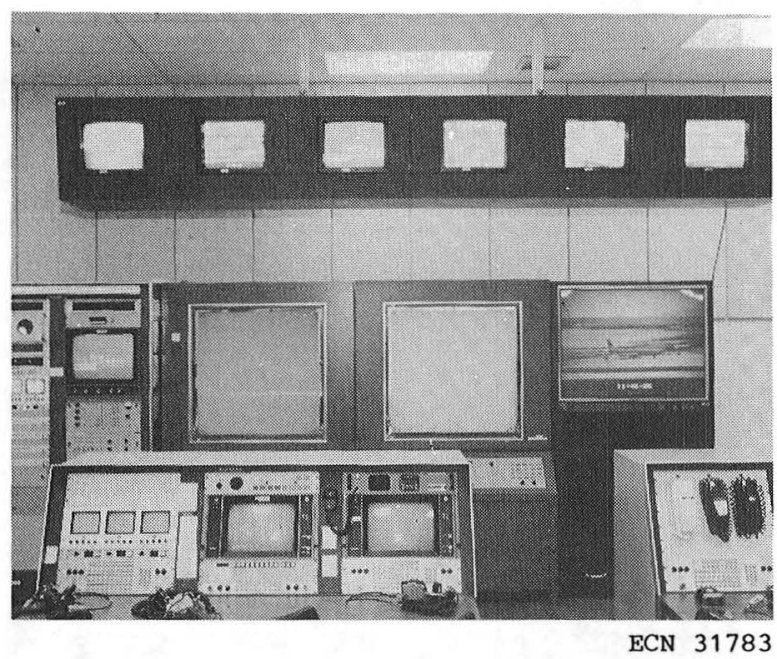

Fig. 17 Blue Room overhead video monitors.

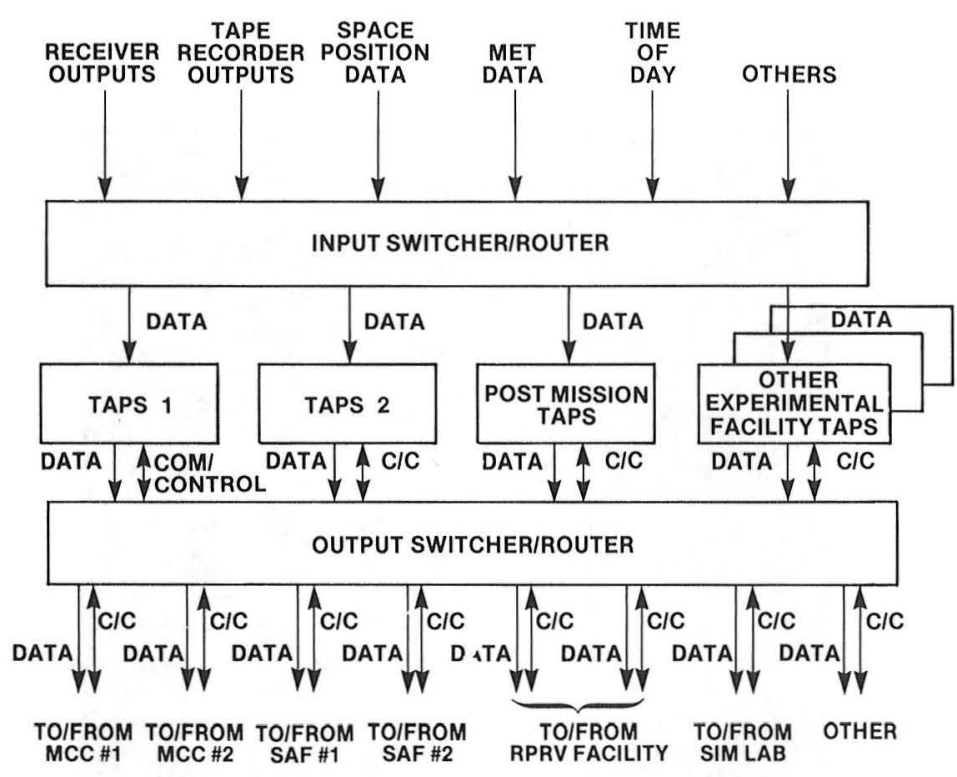

Fig. 18 Overall configuration of telemetry acquisition and processing system. 


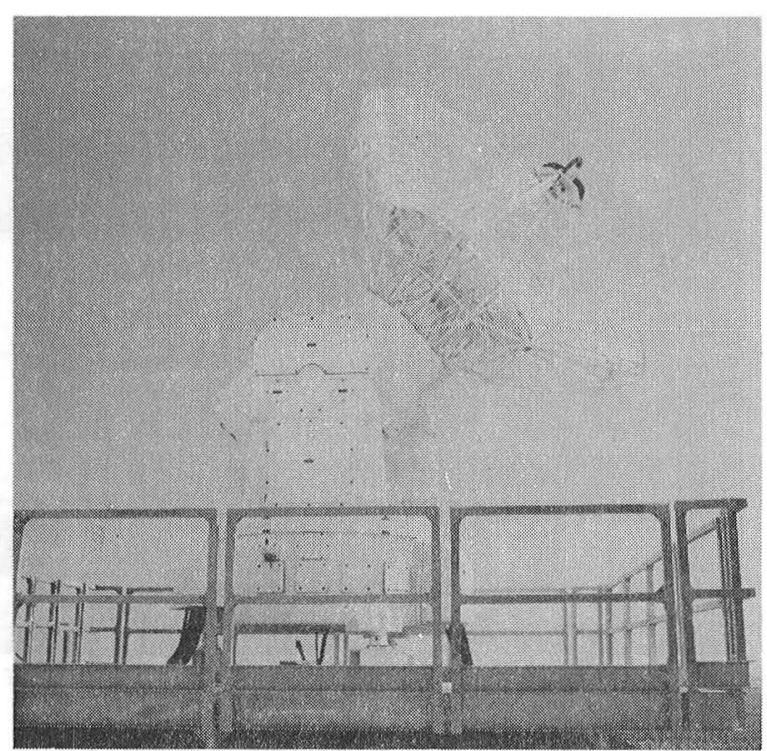

ECN 11120

Fig. 19 Ames-Dryden FPS-16 precision tracking radar.

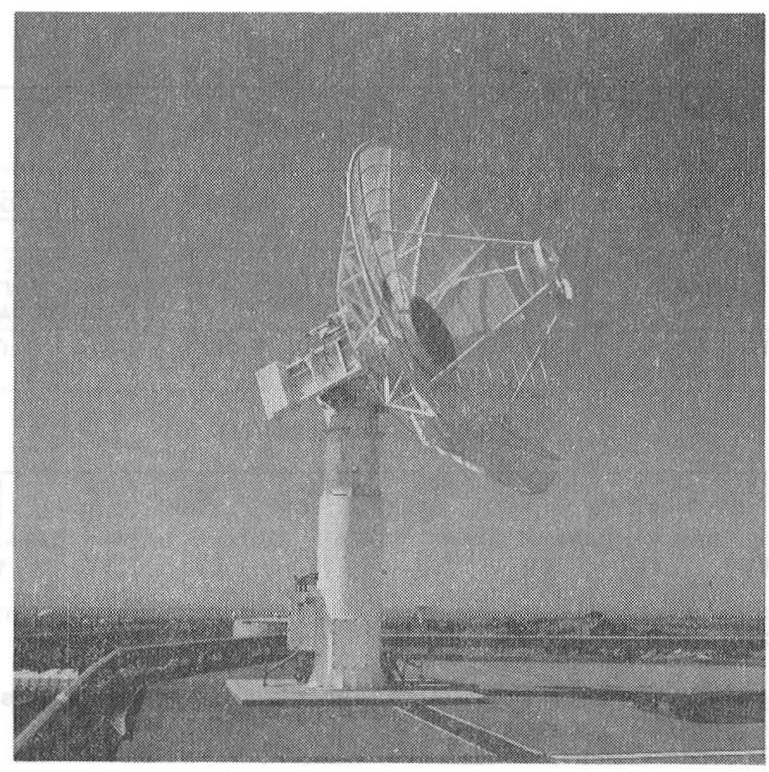

ECN 11124

Fig. 20 Ames-Dryden triplex antenna. 


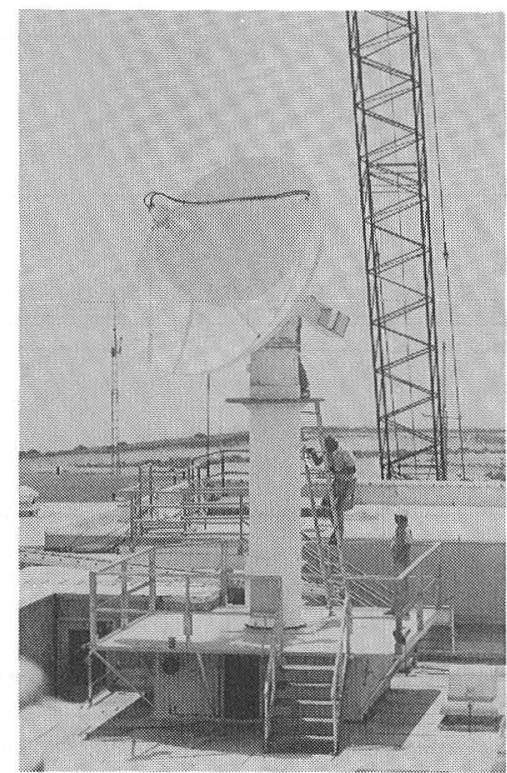

ECN 24379

Fig. 21 Ames-Dryden $S / L$ band telemetry tracking antenna.

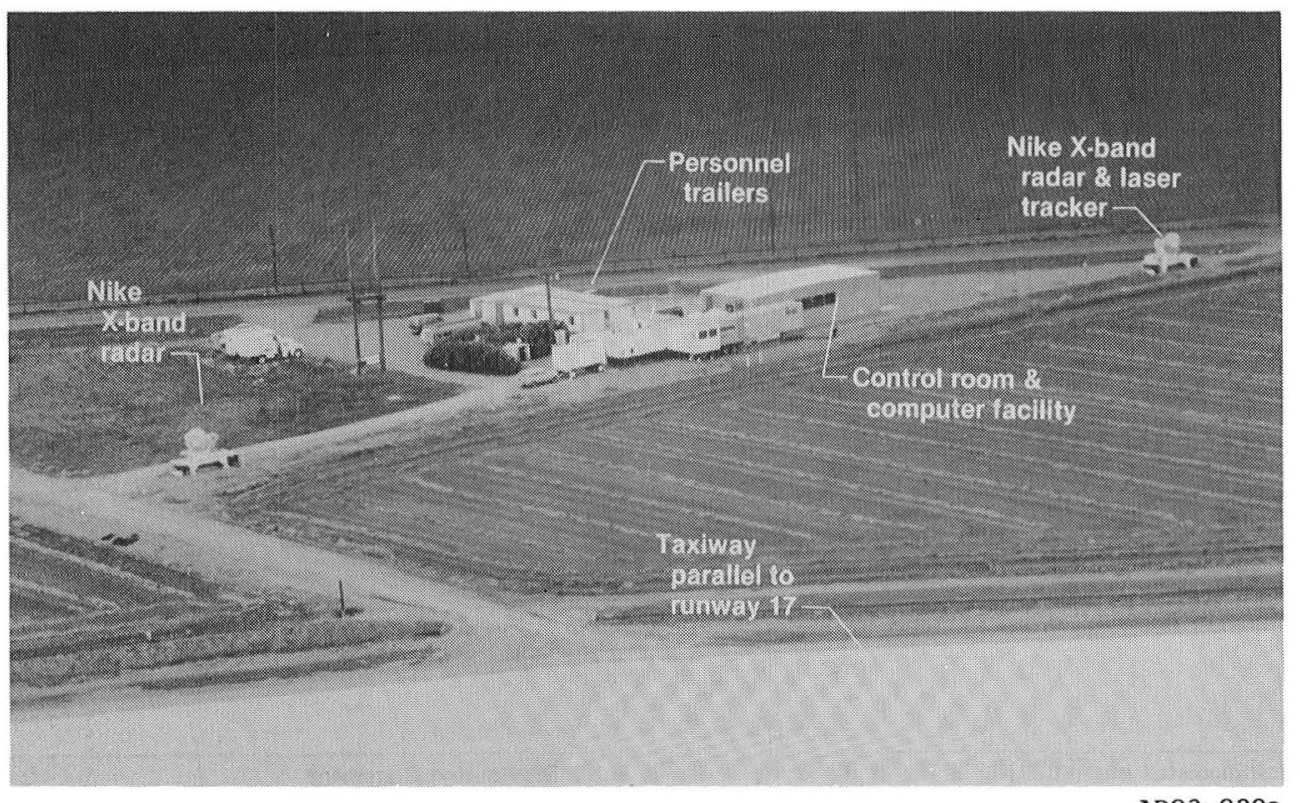

Fig. 22 NALF Crows Landing • 


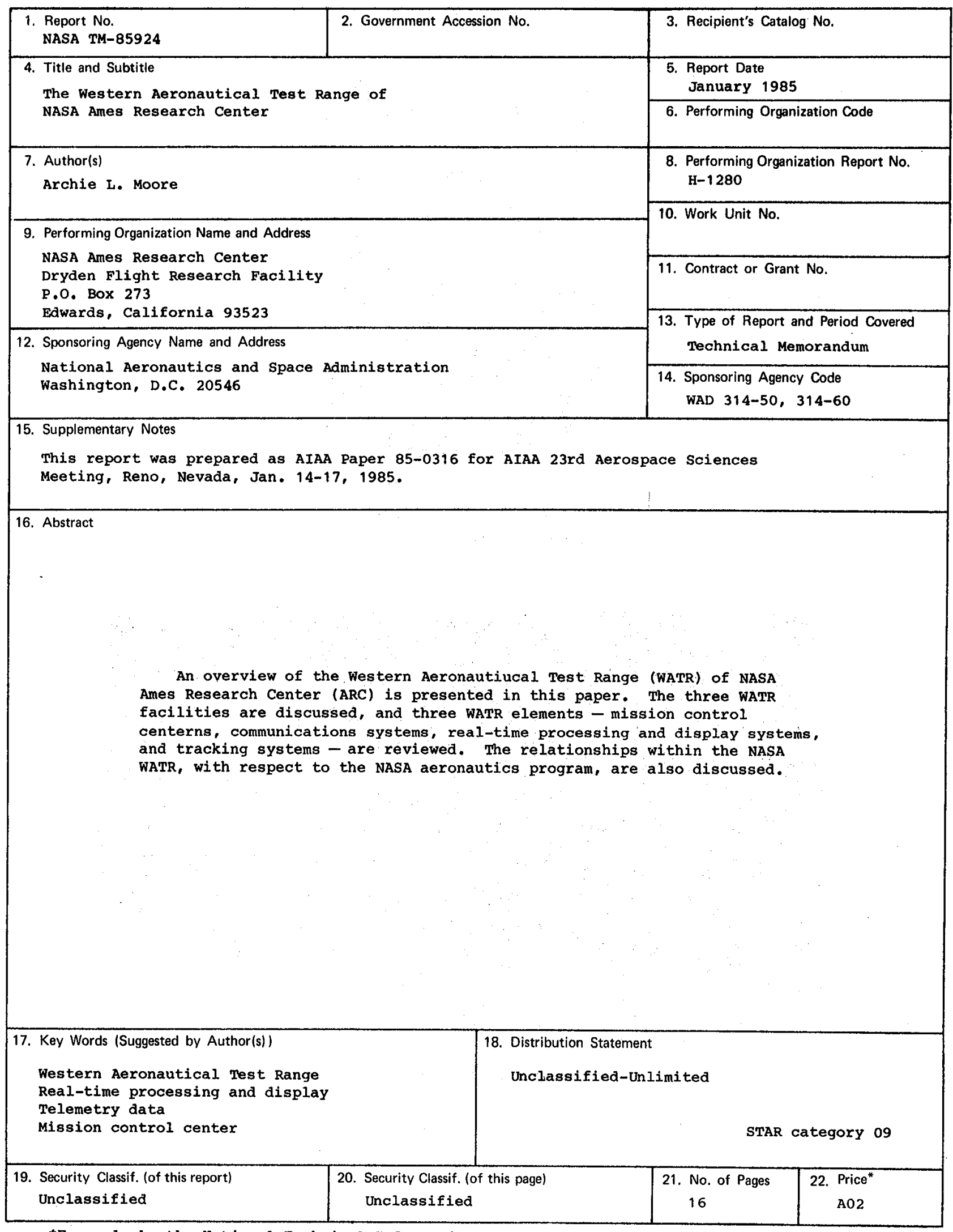

*For sale by the National Technical Information Service, springfield, Virginia 22161. 


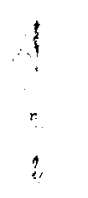

